\title{
Eighth international congress on peer review in biomedical publication
}

\author{
A call for research
}

\author{
Drummond Rennie director ${ }^{12}$, Annette Flanagin executive managing editor ${ }^{3}$, Fiona Godlee editor \\ in $_{\text {chief }}{ }^{4}$, Theodora Bloom executive editor ${ }^{4}$
}

${ }^{1}$ Peer Review Congress, Chicago, Illinois; ${ }^{2}$ Philip R Lee Institute for Health Policy Studies, University of California, San Francisco, California, USA; ${ }^{3} J A M A$ and JAMA Network, Chicago, Illinois, USA; ${ }^{4}$ The BMJ, London, UK

Everyone has a stake in the quality of the biomedical literature. With that in mind, we announce our intention to hold the eighth international congress on peer review in biomedical publication on 10-12 September 2017, in Chicago, Illinois. As with the previous congresses, our aim will be to improve the quality and credibility of biomedical information and to help advance the efficiency, effectiveness, and equitability of dissemination of scientific information throughout the world.

We announced in 1986 that we would sponsor and hold a conference to present the results of research into the process of editorial selection and improvement of scientific manuscripts, constituting peer review. ${ }^{1}$ Each of these congresses, held every four years since 1989 and organised by JAMA and The BMJ, have been devoted to three days of presentations of original research into editorial processes. A successful feature of the congresses is our insistence on giving members of the audience ample time to debate the research presented.

We soon realised that the actual process whereby editors sent manuscripts to reviewers before they reached their decision was only one factor affecting the quality of published papers. The research presented at the congresses, which had started as studies of the mechanics of peer review, gradually began to concentrate on the product of the process. Biases of every sort were documented, ${ }^{2-8}$ and proposals to prevent the biases were made and tested. ${ }^{9-11}$ The congresses have featured research describing poor practices on the parts of authors, reviewers, editors, and journals as well as improvements in these practices and the quality of reporting and publication. ${ }^{12}$ And again, prescriptions for improvements were given and tested.

Surprises keep occurring. Although the process whereby editors make their decisions remains almost as mysterious as at the start, the huge advances in the electronic world have made peer review less expensive, quicker, and more efficient and have allowed important but competing advances and threats to the validity of scientific publication. Thus, we are interested in continuing the evaluation of the quality of reporting and publication and in further developments in quests for openness-open peer review, postpublication public review and comment, open and public access, data transparency, and transparency of contributions, conflicts, and biases-as well as in better ways to serve readers and users of biomedical publication. Electronic advances have also enabled phoney, predatory, and hijacked journals; phony authors; fake reviewers; journals trumpeting their rigorous but phoney peer review; non-existent editors; unaware editorial board members; and misleading performance metrics. ${ }^{13-16}$ All of these, and no doubt newer tricks, will require investigation and their remedies tested, on which we hope to see new research presented and discussed at the next peer review congress. Finally, we remain interested in research into the peer review of grants, peer review as practised in other sciences, and in the testing of types of peer review, new and old.

The peer review congresses have enjoyed collaboration with important groups, such as the EQUATOR (Enhancing the Quality and Transparency of Health Research) Network (www. equator-network.org). For 2017, such collaboration will continue and will include coordination with the research and education programmes of METRICS (Meta-Research Innovation Center at Stanford, http://metrics.stanford.edu). METRICS will be holding its first international meeting at Stanford on 19-21 November 2015, focused on improving research practices, and the second meeting will be coordinated with the peer review congress in 2017. We also plan a formal lively debate on a hot topic that will inform, entertain, and engage the congress participants. We welcome suggestions for hot topics.

We encourage you to start your research now. Abstracts summarising original, high quality research on any aspect of scientific peer review, publication, and information exchange are welcome. Suggested topics of interest include those listed in the box. As with previous congresses, preference will be given to well developed studies with generalisable results (such as prospective studies of multiple journals in a range of 
disciplines, multiyear trials, and controlled studies). Retrospective studies, systematic reviews, bibliometric and other data analyses, surveys, and other types of studies will also be considered. Abstracts that report new research and findings will be given priority.

The deadline for submission of abstracts describing new research is January 2017. Programmes and abstracts of research presented at the previous seven congresses are available on the peer review congress website (www.peerreviewcongress.org). Additional information and future announcements will also be available on the website.

Competing interests: We have read and understood BMJ policy on declaration of interests and declare the peer review congress receives unrestricted grants from various charitable organizations and not for profit and commercial publishers. A list of sponsors of the seventh international congress on peer review and biomedical publication is available at www.peerreviewcongress.org/sponsors.html.

Provenance and peer review: Commissioned; not externally peer reviewed.

This editorial is being simultaneously published in JAMA.

1 Rennie D. Guarding the guardians: a conference on editorial peer review. JAMA 1986;256:2391-2.
2 Dwan K, Altman DG, Clarke M, et al. Evidence for the selective reporting of analyses and discrepancies in clinical trials: a systematic review of cohort studies of clinical trials. PLoS Med 2014;11: e1001666.

3 Emerson GB, Warme WJ, Wolf FM, Heckman JD, Brand RA, Leopold SS. Testing for the presence of positive-outcome bias in peer review: a randomized controlled trial. Arch Intern Med 2010;170:1934-9.

4 Vedula SS, Bero L, Scherer RW, Dickersin K. Outcome reporting in industry-sponsored trials of gabapentin for off-label use. N Engl J Med 2009;361:1963-71.

5 Olson CM, Rennie D, Cook D, et al. Publication bias in editorial decision making. JAMA 2002;287:2825-8.

6 Weber EJ, Callaham ML, Wears RL, Barton C, Young G. Unpublished research from a medical specialty meeting: why investigators fail to publish. JAMA 1998;280:257-9.

7 Garfunkel JM, Ulshen $\mathrm{MH}$, Hamrick HJ, Lawson EE. Effect of institutional prestige on reviewers' recommendations and editorial decisions. JAMA 1994:272:137-8.

8 Chalmers I. Underreporting research is scientific misconduct. JAMA 1990;263:1405-8.

9 Hopewell S, Ravaud P, Baron G, Boutron I. Effect of editors' implementation of CONSORT guidelines on the reporting of abstracts in high impact medical journals: interrupted time series analysis. BMJ 2012;344:e4178.

10 Moher D, Weeks L, Ocampo M, et al. Describing reporting guidelines for health research: a systematic review. J Clin Epidemiol 2011;64:718-42.

11 Hopewell S, Collins GS, Boutron I, et al. Impact of peer review on reports of randomised trials published in open peer review journals: retrospective before and after study. BMJ 2014;349:g4145.

12 International Congress on Peer Review and Biomedical Publication. www. peerreviewcongress.org.

13 Beall's List. Scholarly open access. http://scholarlyoa.com

14 Bohannon J. Who's afraid of peer review? Science 2013;342:60-5.

15 Ferguson C, Marcus A, Oransky I. Publishing: the peer-review scam. Nature 2014;515:480-2.

16 Butler D. Investigating journals: the dark side of publishing. Nature 2013;495:433-5.

\section{Cite this as: BMJ 2015;350:h2411}

(c) BMJ Publishing Group Ltd 2015 


\section{Topics of interest for research on peer review and biomedical publication}

Bias

- Biases on the part of researchers, authors, reviewers, editors, funders or sponsors, commentators, and consumers of biomedical publication

- Publication biases

- Efforts to manage or eliminate biased reporting

Editorial and peer review decision making and responsibilities

- Models of peer review and editorial decision making and workflows used by journals and funders

- Valuations of the quality, validity, and practicality of peer review and editorial decision making

- Quality assurance for reviewers and editors

- Editorial policies and responsibilities

- Editorial freedom and integrity

- Peer review of grant proposals

Research and publication ethics

- Ethical concerns for researchers, authors, reviewers, editors, publishers, and funders

- Authorship, contributorship, and responsibility for published material

- Conflicts of interest

- Research and publication misconduct

- Ethical review and approval of studies

- Confidentiality

- Effects of funding and sponsorship on research and publication

- Influence of external stakeholders: funders, journal owners, advertisers or sponsors, policy makers, legal representatives, and the news media

Evaluations of and mechanisms for improving the quality of reporting

- Effectiveness of guidelines and standards designed to improve the quality of scientific publication

- Evaluations of the quality of published information

- Data sharing, transparency, reliability, and access

- Quality and reliability of data presentation and scientific images

- Quality and use of online supplemental content

- Quality and effectiveness of new forms of scientific articles

Models for peer review and scientific publication

- Open and public access

- Single blind, double blind, and open peer review

- Prepublication posting and release of information

- Embargoes

- Postpublication review, communications, and influence

- Effect of social media

- Changes in readership and usage of peer-reviewed published content

- Presentation, enhancement, and quality of scientific information in multimedia and new media

- Quality, use, and effects of publication and performance metrics and usage statistics

- Quality and influence of advertising and sponsored publication

- Quality and effectiveness of content tagging, mark-up, linking, and structures

- Threats to scientific publication

- The future of scientific publication

Dissemination of scientific and scholarly information

- Methods for improving the quality, efficiency, and equitable distribution of biomedical information

- New technologies that affect the quality, integrity, dissemination, and access of biomedical information

- The impact of social media and new media on science critique and dissemination 